\title{
Status of Slightly Polluted Raw Water Treatment in Chinese Rural Areas
}

\author{
Longlong Zhu ${ }^{1, a}$, Liping Qiu ${ }^{1, b^{*}}$, Lixin Zhang ${ }^{2, c}$, Shoubin Zhang ${ }^{1, d}$,Kang$$
X i e^{1, e}
$$ \\ ${ }^{1}$ School of Civil Engineering and Architecture, University of jinan $\square$ Jinan 250022, China \\ ${ }^{2} \mathrm{Ji}$ Da Hospital, University of Jinan, Jinan 250022, China \\ ajulonaki@163.com, lipingqiu@163.com, Clixinzhang@163.com, dcea_zhangsb@ujn.edu.cn, \\ ecea_xiek@ujn.edu.cn \\ *Corresponding Author
}

Keywords: rural areas; slightly polluted raw water; treatment method

Abstract: Water resources in Chinese rural areas were becoming precious because of the polluted water environment. In this paper, the status of rural areas in China has been reviewed. The typical pollutants in rural raw water bodies were different from urban raw water bodies. In rural water environment, organic matters and ammonia nitrogen concentration were high, heavy metal and other toxic pollutants were low. Enhanced coagulation, enhanced filtration, adsorption, biological oxidation and membranes were the main treating methods. The biological oxidation and membranes technology combination was prospected in future rural slightly polluted raw water treatment.

\section{Introduction}

Chinese vast rivers, lakes and mountains were beyond count and the water resource in China was rich. However, China had a large population and a small amount of water resources per capita, so China was also a country with a serious shortage of fresh water resources. According to statistics, the total amount of water sources in China was about 3 trillion cubic meters, ranking sixth in the world. But the per capita amount was less than the world average ${ }^{[1]}$. In addition, the unreasonable mode of production in developing countries made the shortage of water resources seriously polluted. As one of the gathering places of our country, the environment pollution in rural areas was evident.

Due to the limited knowledge of science and technology and the low level of the economic development, compared with the large and medium-sized enterprises in urban areas, rural areas were more likely to cause environmental pollution. This was mainly because the small township enterprises were miscellaneous in industries, pursuing immediate interests and poor awareness of environmental protection. In rural areas, populations were relatively dispersed while drainage system was not enough to use. The wastewater was discharged straightly into rivers and lakes without treating. This polluted the local raw water and groundwater in the countryside. And in most rural areas, untreated water was pumped to families. This made the health of rural residents be threatened greatly.

\section{Main Reasons of Water Pollution in Rural Areas}

The rapid development of township enterprises 
The township enterprises, as the leader to support the agriculture and to drive the countryside to the well-off, play an important role in the development of the rural economy. However, the rapid development of township enterprises had a serious negative impact on the rural environment. Township enterprises great quantity, small scale and scattered distribution made it difficult to manage. The imperfect supervision and inspection constitution lead to the enterprises pursuing the maximum production and using natural resources wantonly. These measures destructed the natural environment ${ }^{[2]}$. Township enterprises' poor awareness of environmental protection resulted in waste water and other pollutants discharged directly into the water body and caused the pollution of water resources.

Excessive uses of pesticides and fertilizers

With the rise of pesticides, fertilizers and other agricultural products, farmers in pursuit of production used a lot of fertilizer and pesticide in farmlands. The fertilizers and pesticides contained a large number of chemicals. The spare ones would be poured into water bodies by irrigation water or rain water. Excessive fertilization was a common phenomenon in the rural areas in our country. The excess nutrients did not play a role in agriculture. Instead, it was a pollution source.

Pollution of livestock and poultry

Livestock farming was a main part of China's agriculture and also the main source of farmer's economic income. In rural areas, livestock farming conditions were poorer than the large and medium-sized farms, feces and other waste pollution were generally untreated. Because the livestock defecation was uncertainty, the pollution was not point source pollution. There were a lot of bacteria, viruses, sediments, nitrogen and phosphorus in the feces of livestock. In the process of collecting, transporting and treating the feces, the pollutants entered the ecological environment and polluting the water, air and soil.

Pollution of rural domestic sewage

Because the rural economy was relatively backward, a variety of ancillary equipment was not perfect. The pollutants cannot be collected and processed. The main source of rural domestic sewage were from the kitchens, bath water, washing water and flushing water. It was related to the content, the composition of the waste water, pollutant concentration, township residents living habits and living standards ${ }^{[3]}$. Generally speaking, the content of organic matter was higher in rural domestic sewage, and the content of heavy metals and other toxic substances was lower. However, for the majority rural areas, the construction of waste water discharge pipelines was not perfect, so that the sewage directly discharged into the water body, causing water pollution.

\section{Major Pollutants in Rural Water Sources}

The water quality characteristics of slightly polluted raw water in rural areas were different from that in urban areas. The organic matters and ammonia nitrogen concentration were high, heavy metal and other toxic pollutants were low. However, with the rapid development of urbanization, the types and quantity of pollutants were more and more. The structure of water quality became more and more complex.

The high organic matters content would firstly affect the stability of the water quality, breed large volumes of water of autotrophic organisms breeding and lead to disease transmission. Some organic compounds could produce biological enrichment phenomenon, from low concentration to high concentration, resulting in slow aggregation in the human body ${ }^{[4]}$. The organophosphorus pesticides could lead to poisoning. The organochlorine pesticides would accumulate in the fat. The immune function, endocrine function and reproductive function of human and animal were harmed by these 
pollutants. Most of the polycyclic aromatic hydrocarbons had carcinogenic effects.

Nitrogen is one of the typical pollutants in water, mainly divided into organic compounds and ammonia compounds. High ammonia nitrogen in water lead to algae blooms. The "water bloom" phenomenon consumed dissolved oxygen in the water, resulting in a large number of aquatic animals died and causing damage to the ecological system. At the same time, under the action of nitrification bacteria, nitrate nitrogen and nitrite nitrogen could be formed in the water and that could be accumulated in the human bodies. And high ammonia increased the cost of water treatment. And the chloroform would be formed in the chlorination process, which is a typical mutagenic substance.

The heavy metal ions in water were also harmful to human health. Water containing cadmium drunk into the human body would cause kidney, bone and other organs lesions, even lead to death.

The special pollutants in water are more serious harm to human body ${ }^{[5]}$. Special pollutants are different from the general pollutants in the water, the concentration of these substances not only affect the human reproductive ability and nervous system, but also on the human body to produce abnormal, carcinogenic and mutagenic hazards.

\section{Treatment Methods}

\section{Enhanced coagulation}

Enhanced coagulation was based on conventional coagulation process using more effective coagulants and increasing coagulant dosages. This method could realize coagulants adsorption bridging, netting or swept volume. It promoted the removal efficiency of pollutants. Enhanced coagulation was the optimization and improvement of the conventional coagulation process ${ }^{[6]}$. It was a new method and highly efficient water treatment technology for slightly polluted raw water. The removal efficiencies of algae and organic matters in water were significantly influenced by adding coagulant aid and reducing the alkalinity of water. But it had little effect on ammonia nitrogen and assimilable organic matters.

Enhanced filtration

Enhanced filtration was the optimization and improvement of conventional filtration, which was suitable for the treatment of slightly polluted raw water. At present, the commonly used enhanced coagulation process was adding coagulant aid, optimizing the filler and the filter, etc. Enhanced filtration could also be improved through the filter characteristics so that the treatment effect could be better. The combination of biological and filtration was a commonly used method of enhanced filtration. It used enhanced adsorption and biological oxidation to improve the treatment effects of the filter units. With the continuous improvement of filtration theory, the research on the improvement of the filter materials' characteristics was gradually mature, and the removal efficiency of the conventional pollutants in water was remarkable.

Enhanced adsorption

Enhanced adsorption was one of the technical means for the treatment of slightly polluted raw water. Commonly used methods of adsorption included activated carbon adsorption, diatomite adsorption, zeolite adsorption, combined adsorption, etc. Activated carbon adsorption technology was developed, widely used and effective method ${ }^{[7]}$. It could remove the water smell, NOM (Natural Organic Matter) and other micro polluting substances.

Biological oxidation

Oxidation was one of the effective methods to treat slightly polluted raw water. The common methods include chemical oxidation, biological oxidation and photocatalytic oxidation. Chemical oxidation was added strong oxidants in the water supply process and use the oxidant oxidation 
capacity of oxidation to decompose organic pollutants so as to improve the follow-up process and the overall process of treatment. Biological oxidation removed the organic matters and ammonia nitrogen in slightly polluted raw water by microbial metabolic activities ${ }^{[8]}$. It could reduce the load of conventional treatment and advanced treatment and improve the quality of water. The concentrations of organic matters and ammonia nitrogen in slightly polluted raw water were generally very low. Aerobic microorganism in poor nourishment water bodies played a leading role with strong adsorption capacity of organic matter. The adsorption capacity of fillers was also obvious. The microorganism had a long life cycle.

Membrane technology

Membrane technology was unique with its high efficiency, low cost, strong controllability and other characteristics in the current processing technology. The organic membranes were first applied. It had many advantages in aspects, such as the separation of various sizes of particles, the relatively simple preparation, the easy molding and the mature technology. Since then, the research and development of inorganic membranes has attracted more attention ${ }^{[9]}$. Compared With of organic membranes, inorganic membranes had stable structure, pore size distribution, good chemical stability, high temperature resistance, strong acid and alkali resistance, , high mechanical strength, easy regeneration, high flux, long service life and reduce maintenance and replacement costs etc.

\section{Conclusions}

The characteristics of small water sources in rural areas determined the particularity of its treatment methods. Because most of the rural economies were less developed, the use of high cost water treatment is not practical. Conventional processing methods cannot reach the expected target. To the special case of the rural water sources, integrated treatment methods were needed to deal with the water source by setting up equipment with long service life and high strength components. A water treating system could achieve the intended purpose in treating slightly polluted raw water in rural areas. For example, the use of biological methods for pretreatment and high intensity of the membrane technology for depth treatment may be a new situation in treating slightly polluted raw water sources in rural areas. Integrated water treatment equipment research based on biological treatment of high efficiency, energy saving, and other characteristics. It combined with advanced membrane technology in order to ensure the safety of rural polluted water to provide new ideas.

\section{Acknowledgements}

This study was partly supported by National Natural Science Foundation of China (51278225), Science and technology development projects of Shandong province (2013GSF11704), Natural Science Foundation of Shandong province (ZR2013EEQ007, ZR2015EM021), and Science and technology development projects of Jinan(201302079).

\section{References}

[1] D Wang, L Xing, J Xie: Chemosphere Vol.81(2010), p.39.

[2] O D Beeck M, Ruytinx J, M M Smits:Soil Biology and Biochemistry, Vol.86(2015), p.58.

[3] H Qiao, Y Zhou, F Yu: Chemosphere, Vol.141(2015), p.297.

[4] M Vallejo, R M Fresnedo San, Ortiz I:Chemosphere, Vol.118(2015), p.44.

[5] M Yan, D Wang, J Ni: Separation and Purification Technology, Vol.62(2008), p. 401.

[6] M G, S, M P: Science of The Total Environment, Vol.503(2015), p.69. 
[7] A Jain, R Balasubramanian, M P Srinivasan:Chemical Engineering Journal,Vol283(2016), p.789.

[8] S S Sable, P Ghute, PÁlvarez: Catalysis Today, Vol240(2015), p.46-54.

[9] L Fiksdal, T Leiknes: Journal of Membrane Science, Vol279(2006), p. 364. 